\title{
RELATIONSHIP BETWEEN RESPIRATORY, ENDOCRINE, AND COGNITIVE-EMOTIONAL FACTORS IN RESPONSE TO A PHARMACOLOGICAL PANICOGEN
}

\author{
Mark Lyubkin, M.D., Nicholas D. Giardino, Ph.D., and James L. Abelson, M.D. Ph.D.*
}

Background: The cholecystokinin agonist pentagastrin bas been used to study panic attacks in the laboratory and to investigate hypothalamic-pituitaryadrenal axis activity. Its mechanism of panicogenesis remains unclear. Data from other models suggest that respiratory stimulation itself may induce panic, but pentagastrin's effects on respiration are not well established. Data from another model also suggest links between respiratory and HPA axis reactivity and cognitive modulation of both. To further explore these phenomena, we added respiratory measures to a study of cognitive modulation of HPA and anxiety responses to pentagastrin. Methods: Healthy subjects received pentagastrin and placebo injections, with measurement of cortisol and subjective responses, on two different laboratory visits. They were randomly assigned to receive standard instructions or one of two versions of previously studied cognitive interventions (to either facilitate coping or increase sense of control), given before each visit. Capnograph measures of heart rate $(H R)$, respiratory rate $(R R)$, and end-tidal $\mathrm{pCO}_{2}$ were obtained on 24 subjects. Results: Relative to placebo, pentagastrin induced a significant decline in pC $\mathrm{O}_{2}$ with no change in $\mathrm{RR}$. Cortisol and $\mathrm{HR}$ increased, as expected. Cognitive intervention reduced the byperventilatory response to pentagastrin. Conclusions: Pentagastrin stimulates respiration, likely via increases in tidal volume. Respiratory stimulation could play a role in its panicogenic potency, though perhaps indirectly. As with HPA axis responses, bigher-level brain processes may be capable of modulating pentagastrin-induced hyperventilation. This model may be useful for further study of cortical/ cognitive control of interacting emotional, respiratory, and neuroendocrine sensitivities, with potential relevance to panic pathophysiology. Depression and Anxiety 27:1011-1016, 2010.

(C) 2010 Wiley-Liss, Inc.

Key words: HPA axis; respiration; pentagastrin; panic disorder; neuroendocrinology

\section{INTRODUCTION}

Cholecystokinin (CCK) is a widely distributed CNS
peptide thought to play a mediating role in anxiety.
Human studies have shown that the CCK-B agonists,
CCK-4 and pentagastrin, can produce panic attacks in
laboratory models, ${ }^{[2-4]}$ but mechanisms of panicogen-
esis remain unclear. CCK-B agonists may have direct
effects on neural regions mediating components of
anxiety or panic responses, or simply produce side
effects that are interpreted as threatening. Effects on
respiration may also play a role. Direct respiratory
stimulation can itself induce panic, ${ }^{[5,6]}$ but pentagastrin's
Department of Psychiatry, Trauma, Stress and Anxiety Research Group, University of Michigan, Ann Arbor, Michigan

*Correspondence to: James L. Abelson, 4250 Plymouth Rd (Box 5765, Rm. 2733), Ann Arbor, Ml 48109-2700.

E-mail: jabelson@umich.edu

The authors report they have no financial relationships within the past 3 years to disclose.

Received for publication 6 October 2009; Revised 26 May 2010; Accepted 29 May 2010

DOI 10.1002/da.20725

Published online 18 August 2010 in Wiley Online Library (wiley onlinelibrary.com).

(C) 2010 Wiley-Liss, Inc. 
impact on respiration is not well studied. CCK-B agonists may increase respiration by increasing tidal volume $(\mathrm{Vt})$ and not respiratory rate $(\mathrm{RR}),{ }^{[7]}$ though there is some evidence they can increase both $\mathrm{Vt}$ and RR. To our knowledge, there has only been one study that examined the effect of CCK-B on end-tidal, partial pressure of carbon dioxide $\left(\mathrm{P}_{\mathrm{ET}} \mathrm{CO}_{2}\right)$ and its association with panic-like symptoms in healthy humans. The study found that CCK-B did not affect respiratory parameters, ${ }^{[8]}$ but it used a relatively low dose of the CCK-B agonist in order to demonstrate that increase in general arousal does not drive respiratory parameters, and hypothesized a link between CCK-B panic and respiratory parameters that would likely be seen with higher doses of CCK panicogens. Further understanding the normal respiratory effects of laboratory panicogens is important, because sensitivity to $\mathrm{P}_{\mathrm{ET}} \mathrm{CO}_{2}$ in brainstem suffocation alarm centers has been proposed as a putative mechanism underlying panic disorder. $^{[9,10]}$

There is evidence that psychological or cognitive interventions can reduce panic symptom intensity in laboratory models, in part by affecting respiratory measures. Research using the respiratory stimulant doxapram has shown that a cognitive intervention (CI) designed to reduce "catastrophic cognitions" and increase sense of control can significantly attenuate hyperventilatory and panic responses in panic patients. ${ }^{[6]}$ This suggests that respiratory effects of CCK-B agonists may also be modulated by higher cortical processes. The relative contribution of brainstem-level supersensitivities and top-down modulatory dysfunction to respiratory abnormalities in panic has not been extensively examined.

In addition to anxiogenesis, CCK-B agonism also activates the hypothalamic-pituitary-adrenal (HPA) axis, a principal neuroendocrine stress response system, ${ }^{[11-13]}$ but there seems to be little relationship between anxiety and stress system responses. ${ }^{[3,14,15]}$ These data suggest dissociation between autonomic, anxiety, and HPA response to pentagastrin. However, there is evidence that HPA activation and respiratory irregularity are closely linked to each other in panic patients in the doxapram model, ${ }^{[16]}$ suggesting potential value in further examination of cross-system linkages in laboratory models of panic.

To further explore the impact of CCK-B agonism on respiration, we added respiratory monitoring to a larger neuroendocrine study investigating the effects of cognitive/emotional factors as modulators of pentagastrininduced HPA axis activity in healthy subjects. We examined effects of pentagastrin on respiration and the impact of CI (designed to reduce novelty and increase control and coping) on respiratory responses. We hypothesized that pentagastrin would stimulate respiration, evidenced by reduced $\mathrm{P}_{\mathrm{ET}} \mathrm{CO}_{2}$, and that $\mathrm{CI}$ would attenuate this hyperventilation. Given the limitations of an add-on study, these data must be considered preliminary, but are informative for future studies.

\section{METHODS}

\section{DESIGN}

Respiratory data using a hand-held capnograph were obtained on 24 of 40 subjects studied in a pentagastrin challenge paradigm, ${ }^{[17]}$ using a single-blind, placebo-controlled design. The study was reviewed and approved by the University of Michigan Institutional Review Board. Subjects, who were blinded to the condition, always received placebo on the first day and then returned 1-7 days later for the pentagastrin injection. Subjects were randomly assigned to receive either standard instructions or a CI (see below).

\section{SUBJECTS}

Subjects were recruited through advertisement and paid \$200. Informed consent was obtained after the nature of the procedures was explained. Subjects were 18-44 years old and medically healthy, without history of alcohol or drug dependence, recent drug or alcohol abuse (6 months), or past or present psychiatric disorder (by SCID). They were of normal weight, with low levels of tobacco (one subject 10 cigarettes per day and two subjects 1 cigarette every 1-2 days) and alcohol use ( $<5$ drinks per week), and had normal screening labs. Female subjects were pre-menopausal, not on birth control pills, and were studied in the first 10 days after menstruation onset.

\section{PROCEDURES}

Subjects reported at $1 \mathrm{pm}$ for experimental sessions. Use of food and tobacco was prohibited subsequent to their arrival. The investigator administered instructions identically on each visit via a 5 min audio tape for standard instructions or a 9 min tape and a 5 min discussion for the cognitive intervention. An intravenous catheter (saline drip) was inserted into an antecubital vein at approximately 1:30 pm. Subjects rested in bed for $1.5 \mathrm{hr}$ (reading, studying, listening to music) to accommodate to the setting. At $3 \mathrm{pm}$, a capnograph that samples $\mathrm{P}_{\mathrm{ET}} \mathrm{CO}_{2}$ and $\mathrm{RR}$ via a nasal canula, and HR through pulse oximetry, was attached for continuous monitoring until $5.00 \mathrm{pm}$. Baseline blood samples were obtained at $3 \mathrm{pm}$ and $3: 28 \mathrm{pm}$. The investigator returned at $3: 30 \mathrm{pm}$ (behind a curtain, out of subject's awareness) to inject (over $15 \mathrm{sec})$ the placebo or pentagastrin $(0.06 \mu \mathrm{g} / \mathrm{kg}$; Wyeth-Ayerst, Philadelphia, PA, or Calbiochem-Novabiochem, Laufelfingen, Switzerland). Blood samples were obtained 3, 5, 10, 20, 30, 45, and $60 \mathrm{~min}$ after injection.

\section{INSTRUCTIONS}

The Standard Instruction (SI) group received basic instructions describing procedures, apparatus, and common side effects of pentagastrin. The CI group received two additional techniques, labeled "coping" and "control." The coping component included a more detailed description of expectable responses (to reduce novelty) and coaching to attribute these responses to normal reactions to pentagastrin rather than anything dangerous (to facilitate "cognitive coping”). The control component gave subjects permission to use infusion pump controls to stop the drug infusion, if they wished to do so. For the larger neuroendocrine study, the CI group was divided into subgroups (full intervention, coping alone, control alone groups) to dismantle which intervention factor modulates neuroendocrine responses. Details are available elsewhere. ${ }^{[16]}$ Respiratory monitoring was added later in the study only for the last 24 subjects, and for these analyses the CI subgroups were combined. 


\section{MEASURES, INSTRUMENTS, ANALYSES}

The Beck Depression Inventory (BDI), Spielberger State-Trait Anxiety Index (STAI), and Anxiety Sensitivity Index (ASI) were administered at screening. Visual analog scales $(100 \mathrm{~mm}$ lines anchored from "not at all" to "most ever") for anxiety, fear, nervousness, and calm were combined to quantify subjective anxious distress during the experiment. Panic symptoms and pentagastrin side effects were rated on a 4-point scale (none, mild, moderate, severe) using a modified acute panic inventory, ${ }^{[3]}$ and summed to quantify total symptom intensity. $\mathrm{P}_{\mathrm{ET}} \mathrm{CO}_{2}, \mathrm{HR}$, and $\mathrm{RR}$ were recorded using a TIDAL WAVE Sp Handheld Mainstream Capnograph with Pulse Oximetry and Sidestream Sampling (Model 715/B) (Respironics Novametrix, CT). Cortisol was assayed using the Coat-Account assay from Diagnostic Products Corporation (Los Angeles, CA) with a sensitivity of $0.2 \mu \mathrm{g} / \mathrm{dl}$.

Respiratory data were collected for $6 \mathrm{~min}$ before and $3 \mathrm{~min}$ following pentagastrin infusion. The $3 \mathrm{~min}$ cutoff was necessary because subjects verbally described symptoms between 3-5 min after infusion, and speaking disrupts capnograph accuracy. Respiratory and cardiac data were averaged at $64 \mathrm{sec}$ intervals, as the device recorded values every $8 \mathrm{sec}$. Outliers were excluded as follows: $\mathrm{P}_{\mathrm{ET}} \mathrm{CO}_{2}<10$ and $>50, \mathrm{RR}<3$ or $>30$, HR $<30$ or $>160$. Repeated measures analyses of variance (RM-ANOVAs) were used to evaluate treatment (placebo versus pentagastrin), time (pre- to post-injection), and interaction effects for heart rate, $\mathrm{P}_{\mathrm{ET}} \mathrm{CO}_{2}$, and cortisol. Between subjects RM-ANOVA was used to evaluate group (SI versus $\mathrm{CI}$ ), time, and interaction effects for $\mathrm{P}_{\mathrm{ET}} \mathrm{CO}_{2}$. Response measures (post-pentagastrin peak minus baseline) were used in regression analyses.

\section{RESULTS}

Subjects were $25.1 \pm 7.6(\mathrm{SD})$ years old, with equal percentages of males and females $(50 \%)$ in the SI $(n=6)$ and CI $(n=18)$ groups. CI subgroups did not differ from each other on baseline measures or cortisol, $\mathrm{P}_{\mathrm{ET}} \mathrm{CO}_{2}, \mathrm{HR}, \mathrm{RR}$, anxious distress, or panic symptom responses to pentagastrin $(P>3)$. There were no differences between SI and CI groups in age, weight, pentagastrin dose, stress rating, ASI $(6.16 \pm 7.78$ versus $11.22 \pm 4.67)$ or BDI $(1.16 \pm 2.04$ versus $0.94 \pm 1.35)$. The two groups did differ in STAI-trait anxiety $\left(34 \pm 13.49\right.$ versus $\left.25.72 \pm 3.38 ; t_{22}=2.44, P<.03\right)$.

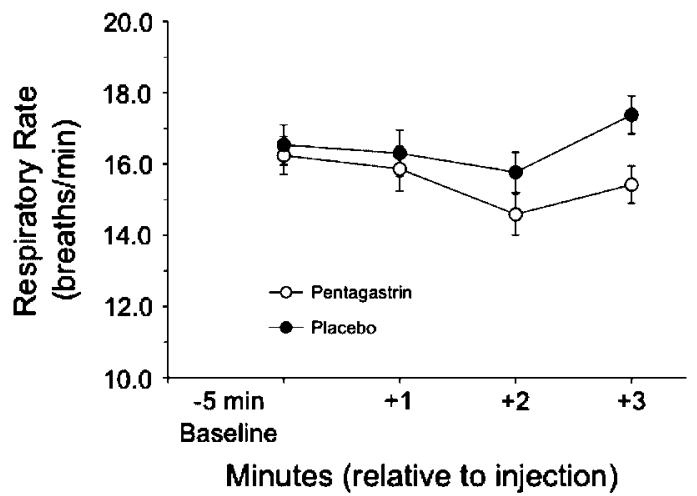

\section{RESPONSE TO DRUG}

Subjects responded differently to pentagastrin than placebo in heart rate (drug-by-time interaction, $\left.F_{3,69}=35.55, \quad P=.0001\right), \quad$ cortisol $\quad\left(F_{6,132}=23.91\right.$, $P=.0001)$, and $\mathrm{P}_{\mathrm{ET}} \mathrm{CO}_{2} \quad\left(F_{3,69}=8.28, P=.0001\right)$, owing to pentagastrin-induced elevations in HR and cortisol and a fall in $\mathrm{P}_{\mathrm{ET}} \mathrm{CO}_{2}$ (Fig. 1), with no placebo day changes. Mean baseline $\mathrm{P}_{\mathrm{ET}} \mathrm{CO}_{2}$ was $41.6 \mathrm{mmHg}$, which dropped to a mean trough of 38.4 within $3 \mathrm{~min}$ post-pentagastrin. The average $\mathrm{P}_{\mathrm{ET}} \mathrm{CO}_{2}$ drop was $3.2 \mathrm{mmHg}$ with a range of $0.1-13.9$. Despite evidence of respiratory stimulation (fall in $\mathrm{P}_{\mathrm{ET}} \mathrm{CO}_{2}$ ), $\mathrm{RR}$ did not change with pentagastrin, but rose slightly with placebo (Fig. 1; drug-by-time interaction effect marginally significant, $F_{3,69}=2.54, P=.06$ ). Subjects reported greater panic symptom intensity $3 \mathrm{~min}$ after pentagastrin $(M=10.67 S D=7.0)$ compared to placebo $(M=0.83 S D=1.71)\left(t_{23}=7.35, P=.0001\right)$. Three out of 24 subjects had a panic attack (at least 4 symptoms rated mild or higher on the acute panic inventory and 2-point or greater increase in anxiety/ fear).

The CI significantly reduced the $\mathrm{P}_{\mathrm{ET}} \mathrm{CO}_{2}$ response to pentagastrin (Fig. 2; group-by-time interaction $\left.F_{3,66}=3.30, P=.03\right)$, but not HR $(F=0.208, P=.89)$ nor $\mathrm{RR}(F=0.89, P=.45)$. STAI-trait anxiety was elevated in the SI group (see above) and controlling for this variable in a repeated measures ANCOVA undermined the significance of the $\mathrm{P}_{\mathrm{ET}} \mathrm{CO}_{2}$ group-by-time interaction $\left(F_{3,63}=1.26, P=.30\right)$. The direct relationship between STAI-trait and $\mathrm{P}_{\mathrm{ET}} \mathrm{CO}_{2}$ was relatively weak $(r=.384, P=.07, n=24)$, especially within the CI group $(r=.064, P=.8, n=18)$.

\section{CORRELATIONS}

The $\mathrm{P}_{\mathrm{ET}} \mathrm{CO}_{2}$ response to pentagastrin correlated with panic symptom intensity $(r=.709, P=.0001, n=24)$, but not with anxious distress $(r=.329, P=.117, n=24)$. The RR response did not correlate with panic symptom intensity $(P>.59)$ or with anxious distress $(P>.37)$. The cortisol response was significantly correlated with the

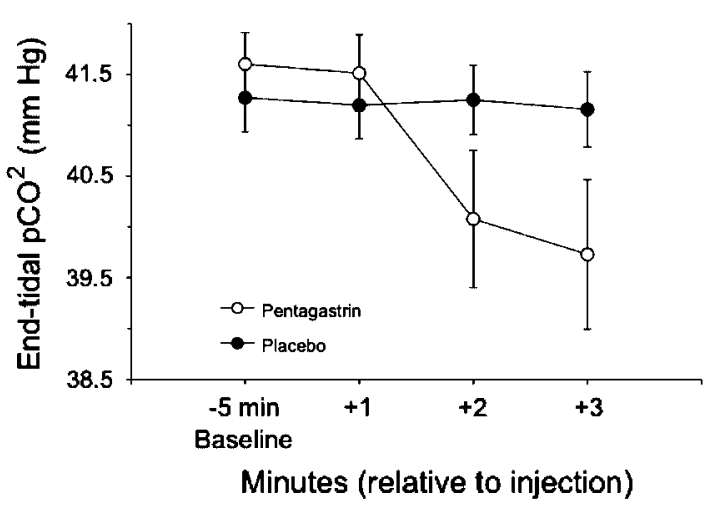

Figure 1. Left panel: Respiratory rate for 24 subjects before and after drug injection on pentagastrin and placebo days (means \pm SE). Right panel: $\mathrm{P}_{\mathrm{ET}} \mathrm{CO}_{2}$ levels before and after injection for 24 subjects on pentagastrin and placebo days (means $\pm \mathrm{SE}$ ). 


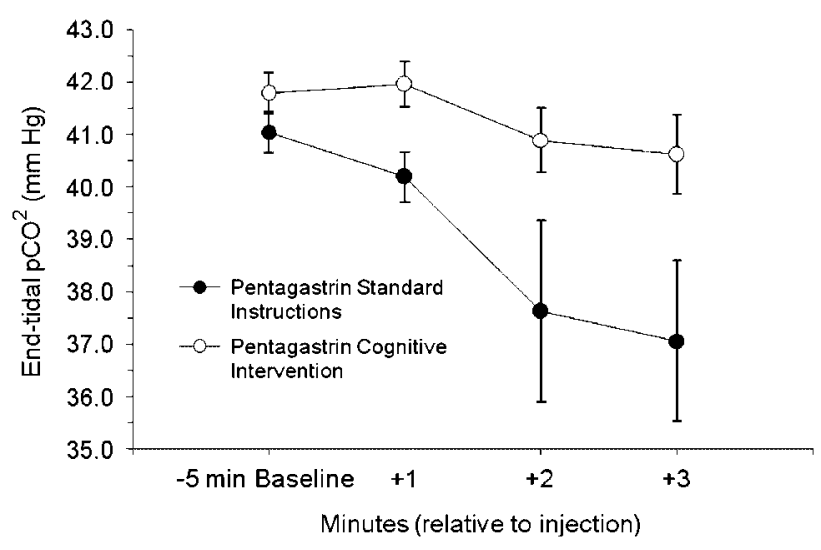

Figure 2. $\mathrm{P}_{\mathrm{ET}} \mathrm{CO}_{2}$ levels (means $\pm \mathrm{SE}$ ) on pentagastrin day for the Standard Instruction group $(n=6)$ and the Cognitive Intervention group $(n=18)$. The cognitive intervention was designed to enhance coping and sense of control.

$\mathrm{P}_{\mathrm{ET}} \mathrm{CO}_{2}$ response $(r=.417, P=.048, n=23)$, but not with the RR response $(P=.48)$.

To insure that significant correlations were not secondary to SI/CI group differences, they were repeated in the CI group alone $(n=18) . \mathrm{P}_{\mathrm{ET}} \mathrm{CO}_{2}$ remained correlated with panic symptom intensity response $(r=.64, P=.015)$ and cortisol $(r=.564, P=.015)$.

\section{DISCUSSION}

These data indicate that pentagastrin is a respiratory stimulant that can produce transiently increased ventilation in healthy subjects and suggest that it does so by increasing tidal volume. Unfortunately, we did not have the instrumentation to record $\mathrm{Vt}$, so direct evidence for its increase is still needed. Nonetheless, the fall in $\mathrm{P}_{\mathrm{ET}} \mathrm{CO}_{2}$ without change in RR strongly suggests that $\mathrm{Vt}$ increased. The only study to our knowledge that looked at the impact of a related CCK-B agonist (CCK4) on $\mathrm{P}_{\mathrm{ET}} \mathrm{CO}_{2}$ found no effect. ${ }^{[8]}$ An earlier study that did not measure $\mathrm{P}_{\mathrm{ET}} \mathrm{CO}_{2}$ did directly demonstrate hyperventilation in response to CCK4, driven by Vt and not RR. ${ }^{[7]}$ However, another study using pentagastrin showed changes in both $\mathrm{Vt}$ and RR in healthy subjects. ${ }^{[18]}$ These discrepancies may reflect differences in drug doses or subject characteristics. The Schruers et al. study purposely used a low drug dose to examine effects of arousal and showed no effect on respiratory parameters despite small but statistically significant effects on heart rate, panic, and anxiety symptoms. The Lara et al. study used a higher dose and examined only those subjects who responded to pentagastrin with panic, and was the only one to show an effect on RR. The CCK4 study and our study included many subjects who did not panic. Increased RR may be a function of panic and not a direct drug effect, whereas reduction in $\mathrm{P}_{\mathrm{ET}} \mathrm{CO}_{2}$, likely owing to $\mathrm{Vt}$ increase, may be a direct drug effect that is dose dependent. A recent study of blood phobia suggests that Vt increase may be more strongly linked to physical symptoms (e.g., dizziness and feeling faint) than $\mathrm{RR}$, and may play a more prominent role in anxiety. ${ }^{[19]}$ If pentagastrin directly stimulates increases in tidal volume, this may well contribute to its panicogenic potency in vulnerable subjects, with additional respiratory drive that leads to increased RR appearing secondarily when panic in fact occurs.

If respiratory stimulation does contribute to pentagastrin-induced panicogenesis, the precise pathway remains unclear, and this study of healthy subjects can provide only limited information. However, the correlation between $\mathrm{P}_{\mathrm{ET}} \mathrm{CO}_{2}$ and panic symptom intensity was driven in our subjects entirely by physical symptom ratings, in the absence of any link to anxious distress. Though the total amount of hyperventilation produced was relatively mild (mean drop of $3.17 \mathrm{mmHg}$ in $\mathrm{P}_{\mathrm{ET}} \mathrm{CO}_{2}$ ), those subjects with the greatest falls were the ones who reported developing physical symptoms. This suggests that if respiratory stimulation plays a role in pentagastrin's panic symptom generation it might do so indirectly through hyperventilation-related physical sensations, rather than via a direct link between respiratory control centers and anxiogenesis. Such physical sensations may have particular salience to panic-prone people, either because they are reminiscent of previously experienced panic attacks or because they may have particular salience to processors in the brain that attach affective tone to bodily sensations (see below). Such indirect pathways are consistent with growing evidence that respiratory abnormalities are not a fundamental feature of patients with panic disorder, ${ }^{[20,21]}$ so respiratory centers may not play as central a role in panic as once thought. ${ }^{[9]}$

Other pathways are clearly possible and further research is needed. The link between hyperventilation and physical symptoms in this study was correlational and the overall group reductions in $\mathrm{P}_{\mathrm{ET}} \mathrm{CO}_{2}$ were not large, so it is possible that the physical sensations reminiscent of panic reported by our subjects were not a consequence of hyperventilation itself. Pentagastrin could produce panic through other pathways, such as hypersensitive CCK-B receptors in the amygdala, ${ }^{[22]}$ which could cause both increased respiratory drive and physical sensations, even without a direct link between the two.

As with doxapram, a CI designed to reduce novelty and increase coping and sense of control significantly attenuated the hyperventilation produced by pentagastrin. This suggests that whatever the mechanism of CCK-B-mediated respiratory stimulation, top-down modulation through higher-level processing of the sensory experiences can attenuate it. The strength of this conclusion is weakened by the fact that some of the variance in respiratory response was captured by a group difference in trait anxiety. Further work with larger and better matched groups is needed to clarify whether CI reduced hyperventilation in the CI group 
or trait anxiety increased hyperventilation in the SI group. Interestingly, neither state nor trait anxiety directly predicted respiratory response. We hypothesize that both the CI and trait anxiety contributed to the group difference detected but, with a small sample, we did not have sufficient power to see the independent effects of both. Though there are a variety of mechanisms through which trait anxiety could impact respiration, a trait anxiety effect, like the CI effect, is compatible with the hypothesis that higher order, cortical, and/or limbic inputs can modulate outputs of physiological control centers and may be relevant to psychophysiological abnormalities detected in patients with anxiety disorders.

Growing evidence supports the hypothesis of bi-directional interaction between cortical-limbic/ cognitive-emotional control circuits in the brain and respiratory phenomena. Shortness of breath or air hunger is a highly distressing experience that activates limbic and paralimbic brain regions, including anterior insula and cingulate, amygdala, thalamus, and basal ganglia. ${ }^{[23,24]}$ As with pain, the affective dimension of this experience is processed separately from the sensory intensity dimension, ${ }^{[25]}$ with affective evaluation processed through limbic pathways (involving insular cortex, amygdala, cingulate cortex, and medial thalamus). ${ }^{[26]}$ These limbic regions are in turn linked to respiratory control centers, providing a loop through which affective experience can be generated by respiratory-related sensations and can in turn shape autonomic and respiratory responses. ${ }^{[27,28]}$ Intriguingly, limbic regions involved in emotional processing, such as insula, amygdala, and hippocampus, may be particularly involved in modulating the phasic aspects of breathing that produce sighs, ${ }^{[29-32]}$ which may have particular relevance to anxiety disorders. ${ }^{[3,34]}$ There is evidence that these same regions provide cognitive-emotional modulation of HPA axis activity, ${ }^{[35]}$ and shared links to the same cognitive-emotional control regions may create the link between HPA axis reactivity and $\mathrm{P}_{\mathrm{ET}} \mathrm{CO}_{2}$ seen in this study. An even stronger link between the HPA axis and respiration was seen in our doxapram study, where the respiratory-dependent variable was rhythm irregularity created by sighs. ${ }^{[16]}$ A similar link may well have been seen here, but the capnograph unfortunately did not provide us with the $\mathrm{Vt}$ date needed to track sighs. Deeper understanding of potential linkages between anxiety, sighs, and HPA axis activity that may be created by shared modulation through top-down cognitive control regions of the brain could be extremely helpful in efforts to dissect the central pathophysiology of a number of psychiatric disorders. $^{[36]}$

These data have significant limitations, including a small sample size, an unexpected group difference in trait anxiety despite random assignment, and an absence of Vt measures. However, they have implications for future studies. Potential links between HPA axis reactivity and respiratory abnormalities in anxious patients may be particularly useful clues to pursue, because shared input from cortical-limbic processors may provide the common thread that helps locate the real source of the dysregulation that creates abnormalities in both systems. Further study of the interactions between HPA axis and respiratory dysregulation in psychiatric disorders may be quite fruitful. It will be important in future work to utilize technology that allows simultaneous measurement of tidal volume, $\mathrm{P}_{\mathrm{ET}} \mathrm{CO}_{2}, \mathrm{RR}$, and HPA axis hormones.

\section{CONCLUSION}

We found that in a healthy population, pentagastrin stimulates respiration, likely via increases in tidal volume, and that respiratory stimulation could play a role in its panicogenic potency through hyperventilation-related physical sensations. Additionally, pentagastrin-induced hyperventilation can perhaps be modulated by a CI, which also attenuates both panic and HPA responses. Although the strength of this conclusion is weakened by a trait anxiety confound between groups, the trait anxiety effect, like the CI effect, is compatible with the hypothesis that higher order, cortical, and/or limbic inputs can modulate outputs of physiological control centers and may be relevant to psychophysiological abnormalities detected in patients with anxiety disorders.

\section{REFERENCES}

1. Bradwejn J, Koszycki D. Cholecystokinin and panic disorder: past and future clinical research strategies. Scand J Clin Lab Invest Suppl 2001;234:19-27.

2. Bradwejn J, Koszycki D, Meterissian G. Cholecystokinintetrapeptide induces panic attacks in patients with panic disorder. Can J Psychiatry 1990;35:83-85.

3. Abelson JL, Nesse RM. Pentagastrin infusions in patients with panic disorder I. Symptoms and cardiovascular responses. Biol Psychiatry 1994;36:73-83.

4. Koszycki D, Zacharko RM, Le Melledo JM, Bradwejn J. Behavioral, cardiovascular, and neuroendocrine profiles following CCK-4 challenge in healthy volunteers: a comparison of panickers and nonpanickers. Depress Anxiety 1998;8:1-7.

5. Lee YJ, Curtis GC, Weg JG, Abelson JL, Modell JG, Campbell K. Panic attacks induced by doxapram. Biol Psychiatry 1993;33: 295-297.

6. Abelson JL, Nesse RM, Weg JG, Curtis GC. Respiratory physiology and anxiety: cognitive intervention in the doxapram model of panic. Psychosom Med 1996;58:302-313.

7. Bradwejn J, LeGrand J-M, Koszycki D, Bates J, Bourin M. Effects of cholecystokinin tetrapeptide on respiratory function in healthy volunteers. Am J Psychiatry 1998;155:280-282.

8. Schruers K, Caycedo N, Overbeek T, Buchold H, Bourin M, Griez E. Effects of low-dose cholecystokinin on respiratory function in healthy volunteers. Eur Neuropsychopharmacol 2000;10: $419-421$.

9. Klein DF. False suffocation alarms, spontaneous panics, and related conditions: an integrative hypothesis. Arch Gen Psychiatry 1993;50:306-317. 
10. Ley R. Panic disorder and agoraphobia: fear of fear or fear of the symptoms produced by hyperventilation? J Behav Ther Exp Psychiatry 1987;18:305-316.

11. Mezey E, Reisine TD, Skirboll L, Beinfeld M, Kiss JZ. Role of cholecystokinin in corticotropin release: coexistence with vasopressin and corticotropin-releasing factor in cells of the rat hypothalamic paraventricular nucleus. Proc Natl Acad Sci USA 1986;83:3510-3512.

12. Kamilaris TC, Johnson EO, Calogero AE, et al. Cholecystokininoctapeptide stimulates hypothalamic-pituitary-adrenal function in rats: role of corticotropin-releasing hormone. Endocrinology 1992;130:1764-1774.

13. Abelson JL, Liberzon I. Dose response of adrenocorticotropin and cortisol to the CCK-B agonist pentagastrin. Neuropsychopharmacology 1999;21:485-494.

14. Khan S, Liberzon I, Abelson JL. Effects of propranolol on symptom and endocrine responses to pentagastrin. Psychoneuroendocrinology 2004;29:1163-1171.

15. Abelson JL, Liberzon I, Young EA, Khan S. Cognitive modulation of the endocrine stress response to a pharmacological challenge in normal and panic disorder subjects. Arch Gen Psychiatry 2005;62:668-675.

16. Abelson JL, Khan S, Lyubkin M, Giardino N. Respiratory irregularity and stress hormones in panic disorder: exploring potential linkages. Depress Anxiety 2008;25:885-887.

17. Abelson JL, Khan S, Liberzon I, Erickson TM, Young EA. Effects of perceived control and cognitive coping on endocrine stress responses to pharmacological activation. Biol Psychiatry 2008;64:701-707.

18. Lara N, Chrapko WE, Archer SL, Bellavance F, Mayers I, Le Melledo JM. Pulmonary and systemic nitric oxide measurements during CCK-5-induced panic attacks. Neuropsychopharmacology 2003;28:1840-1845.

19. Ritz T, Wilhelm FH, Meuret AE, Gerlach AL, Roth WT. Do blood phobia patients hyperventilate during exposure by breathing faster, deeper, or both? Depress Anxiety 2009;26: E60-E67.

20. Pfaltz MC, Michael T, Grossman P, Blechert J, Wilhelm FH. Respiratory pathophysiology of panic disorder: an ambulatory monitoring study. Psychosom Med 2009;71: 869-876.

21. Pfaltz MC, Grossman P, Michael T, Margraf J, Wilhelm FH. Physical activity and respiratory behavior in daily life of patients with panic disorder and healthy controls. Int J Psychophysiol 2010, epub ahead of print.
22. Harro J. CCK and NPY as anti-anxiety treatment targets: promises, pitfalls, and strategies. Amino Acids 2006;31:215-230.

23. Evans KC, Banzett RB, Adams L, McKay L, Frackowiak RS, Corfield DR. BOLD fMRI identifies limbic, paralimbic, and cerebellar activation during air hunger. J Neurophysiol 2002;88: $1500-1511$.

24. Banzett RB, Mulnier HE, Murphy K, Rosen SD, Wise RJS, Adams L. Breathlessness in humans activates insular cortex. Neuroreport 2000;11:2117-2120.

25. Banzett RB, Pedersen SH, Schwartzstein RM, Lansing RW. The affective dimension of laboratory dyspnea: air hunger is more unpleasant than work/effort. Am J Respir Crit Care Med 2008;177:1384-1390.

26. von Leupoldt A, Sommer T, Kegat S, et al. The unpleasantness of perceived dyspnea is processed in the anterior insula and amygdala. Am J Respir Crit Care Med 2008;177:1026-1032.

27. Craig AD. How do you feel now? The anterior insula and human awareness. Neuroscience 2009;10:59-70.

28. Critchley HD. Neural mechanisms of autonomic, affective, and cognitive integration. J Comp Neuro 2005;493:154-166.

29. Kristensen MP, Poe GR, Rector DM, Harper RM. Activity changes of the cat paraventricular hypothalamus during phasic respiratory events. Neuroscience 1997;80:811-819.

30. Harper RM, Poe GR, Rector DM, Kristensen MP. Relationships between hippocampal activity and breathing patterns. Neurosci Biobehav Rev 1998;22:233-236.

31. Poe GR, Kristensen MP, Rector DM, Harper RM. Hippocampal activity during transient respiratory events in the freely behaving cat. Neuroscience 1996;72:39-48.

32. Evans KC, Dougherty DD, Scannell E, McCallister A, Lazar SW. fMRI reveals synchronized limbic and brainstem activity with sigh breaths (poster). Anxiety Disorders Association of America 29th Annual Conference. Alburquerque, NM; 2009.

33. Abelson JL, Weg JG, Nesse RM, Curtis GC. Persistent respiratory irregularity in patients with panic disorder. Biol Psychiatry 2001;49:588-595.

34. Wilhelm FH, Pfaltz MC, Grossman P, Roth WT. Distinguishing emotional from physical activation in ambulatory psychophysiological monitoring. Biomed Sci Instrum 2006;42:458-463.

35. King AP, Abelson JL, Britton JC, Phan KL, Taylor SF, Liberzon I. Medial prefrontal cortex and right insula activity predict plasma ACTH response to trauma recall. Neuroimage 2009;47:872-880.

36. Abelson JL, Khan S, Giardino ND. HPA axis, respiration and the airways in stress-a review in search of intersections. Biol Psychol 2010;84:57-65. 